\title{
myBas driving cycle for Kuala Terengganu city
}

\author{
J. S. Norbakyah ${ }^{1}$, M. I. Nordiyana ${ }^{2}$ I. N. Anida ${ }^{3}$, A. F. Ayob ${ }^{4}$, A. R. Salisa ${ }^{5}$ \\ 1,2,3,4,5 Faculty of Ocean Engineering Technology and Informatics, Universiti Malaysia Terengganu, Terengganu, Malaysia \\ ${ }^{1,5}$ Renewable Energy and Power Research Interest Group (REPRIG), Universiti Malaysia Terengganu, \\ Terengganu, Malaysia. \\ ${ }^{1.5}$ Energy Storage Research Group (ESRG), Universiti Malaysia Terengganu, Terengganu, Malaysia
}

\section{Article Info}

Article history:

Received May 28, 2020

Revised Sep 19, 2020

Accepted Oct 2, 2020

\section{Keywords:}

Driving cycle

Emissions

Fuel consumption

Micro-trips

myBAS

\begin{abstract}
Driving cycles are series of data points that represent vehicle speed versus time sequenced profile developed for specific road, route, city or certain location. It is widely utilized in the application of vehicle manufacturers, environmentalists and traffic engineers. Since the vehicles are one of the higher air pollution sources, driving cycle is needed to evaluate the fuel consumption and exhaust emissions. The main objectives in this study are to develop and characterize the driving cycle for myBAS in Kuala Terengganu city using established k-means clustering method and to analyse the fuel consumption and emissions using advanced vehicle simulator (ADVISOR). Operation of myBAS offers 7 trunk routes and one feeder route. The research covered on two operation routes of myBAS which is Kuala Terengganu cityfeeder and from Kuala Terengganu to Jeti Merang where the speed-time data is collected using on-board measurement method. In general, driving cycle is made up of a few micro-trips, defined as the trip made between two idling periods. These micro-trips cluster by using the k-means clustering method and matrix laboratory software (MATLAB) is used in developing myBAS driving cycle. Typically, developing the driving cycle based on the realworld in resulting improved the fuel economy and emissions of myBAS.
\end{abstract}

This is an open access article under the CC BY-SA license.

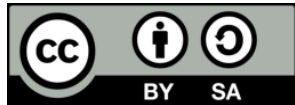

\section{Corresponding Author:}

A. R. Salisa

Faculty of Ocean Engineering Technology and Informatics

Universiti Malaysia Terengganu

21030 Kuala Nerus, Terengganu, Malaysia

Email: salisa@umt.edu.my

\section{INTRODUCTION}

Nowadays, there are wide variety of standard driving cycles that used to implement state emission management. The standard driving cycles in a foreign country such as the United States federal test procedure (FTP-75) and European test cycle (ECE-15) used for energy consumption test of the heavy-duty hybrid vehicle. These driving cycles are applied in the area of invention vehicle emission regulations, design, and advancement of the new car model, assessment of pollutant emission and fuel consumption's measurement in distinct areas [1,2]. Driving cycle can be defined as a series of data points representing speed versus time [3], speed and gear selection as a function of time [4], speed versus distance [5] or time versus gradient [6] in a definite region or a part of a road section. Therefore, this can sufficiently describe the capability quality of vehicle during driving are essential prerequisites for accurate evaluations of vehicles energy economy and emissions performances [7-10].

Considering the vehicle fuel consumption and emissions are influenced by performing situations [11], specific driving cycles are essentials to version a portrait of fuel consumption and atmospheric 
emissions induced by fleets of vehicles. Air pollution is a large-scale complication for big cities, where vehicles are one of the most critical air pollution sources [12,13]. Driving cycles are required for the estimation of fuel consumption and exhaust emissions from vehicles for emission testing and certification, with many cities having unique cycles for different types of vehicles and roads. Thus, perfecting the driving cycle construction technique and the enlargement of driving cycle for local city has practical significances and standards. Route selection, data collection, cycle construction, and cycle assessment have been acknowledged as four major common steps in driving cycle development. Therefore, myBAS is chosen as an example of heavy-duty vehicle in Kuala Terengganu.

Driving cycles act as a standardized measurement proceeding for the certification and interpretation of the fuel economy, emissions and driving range of materializing vehicular technologies. A common example of a legislative certification driving cycle for type approval for light-duty vehicles in Europe is the new european driving cycle (NEDC) and the FTP-75. The reason for the elementary role of driving cycles is that they provide constraints that vehicles have to entertain and where the cost, fuel consumption, and the pollutant emissions are all dependent on the driving cycle [14-17].

The objectives of this research are to develop and characterize the driving cycles for myBAS in Kuala Terengganu city and analyse the fuel consumption and emissions of myBAS. Apart from it, myBAS utility aims are to link the urban and rural areas more efficiently through timetable schedules to help locals make it accessible to get back and forth to work, school and other locations. The land public transport commission (SPAD) held a contract signing ceremony with MARA Liner Sdn Bhd, signaling the pre-launch of myBAS Kuala Terengganu service under the stage bus service transformation (SBST) programme. Besides, the improved myBAS service in Kuala Terengganu will enable commuters in Kuala Terengganu and adjacent areas to enjoy wider connectivity and integration resulting in more reliable bus service across the city.

Furthermore, the development of a real-world driving cycle is important for traffic and transport management, vehicular pollution measurement and control, energy and fuel consumption studies [18]. In this research, matrix laboratory (MATLAB) is used for the derivation of development myBAS driving cycle. Actual driving cycles are the cycles that derived from the movement of test vehicle on the road under real traffic conditions. These cycles are synthesized from real micro trips. These driving cycles are more representative of the intended driving pattern and are generally constructed with a simple pattern to obtain high repeatability [19]. Therefore, the verification of driving cycles with well-established codes and software also be comprised.

\section{RESEARCH METHOD}

A complete methodology is designed in developing myBAS driving cycle as illustrated in Figure 1 . The main steps of methodology are presented briefly below. In this research, only one sort of vehicle is used which is myBAS that operated in Kuala Terengganu. myBAS is a valuable example of heavy-duty vehicle that used by the citizen in Kuala Terengganu. This driving cycle development can help myBAS to reduce fuel consumption and emission. The number of routes is limited into two types of routes. The routes that have been selected is F100, the Kuala Terengganu city feeder and T102 routes where the destination is from Kuala Terengganu to Jeti Merang.

Each selected route has to be repeated 10 times in order to obtain an exact data. The F100 route has the highest percentage of people utilizing myBAS because the routes indicate the main point of city where all the facilities and accommodations are located. Besides, the T102 route is demand for the local to go from one destination to another nearest destination. Global positioning system (GPS) is used as a tracking tool and recording the driving pattern along the study area. The collected data then will be divided into several microtrips, and features such as average velocity and idle percentage will be calculated from each micro-trip. In developing the final driving cycle for Kuala Terengganu city, the k-means clustering method is used for both route 1 and route 2 . ADVISOR software is used in analysis the fuel consumption and emissions that based on the final develop driving cycle. ADVISOR is used because the software is an established software in simulation studied.

In order to characterize the driving cycle test run data, nine assessment parameters are chosen as illustrated in Table 1. Those parameters are average speed, average running speed, average acceleration of all acceleration phases, average deceleration of all deceleration phases, time proportion of idling, time proportion of acceleration, time proportion of cruise, time proportion of deceleration, and root mean square of acceleration [20-23]. 


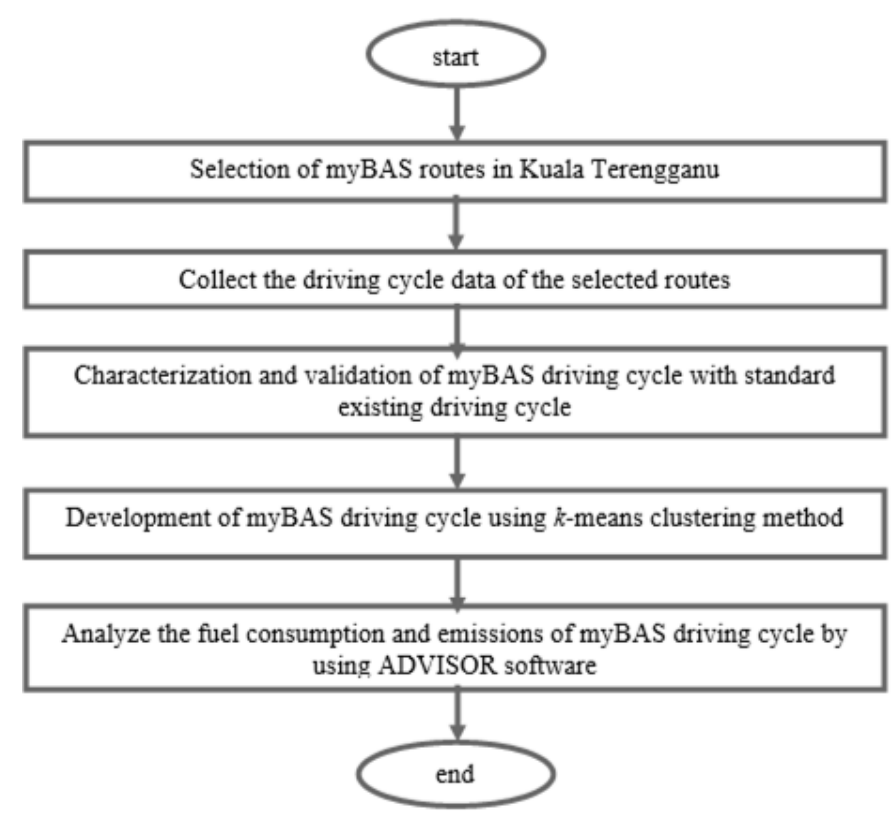

Figure 1. Flow chart of development myBAS driving cycle

Table 1. Nine parameters of driving cycle

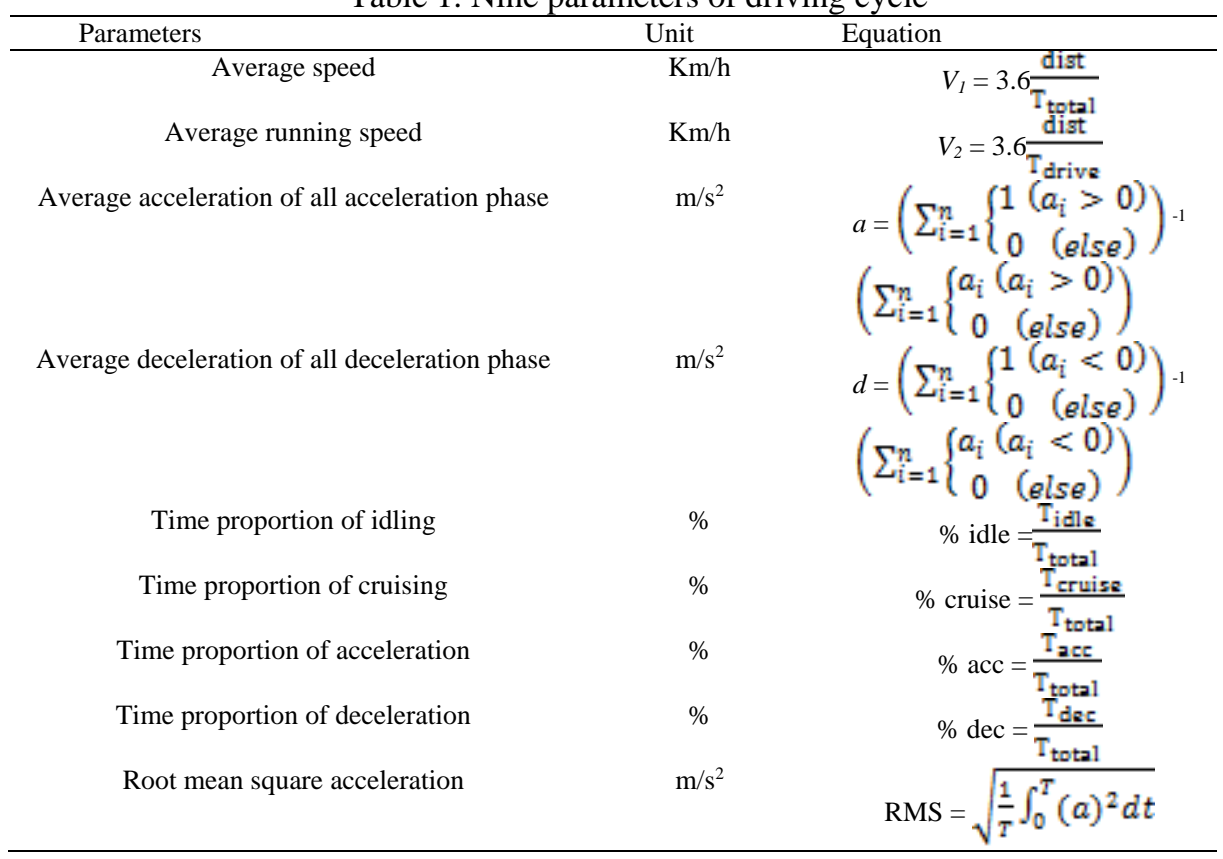

\subsection{Selection of route}

Selection of route is one of the major features in developing driving cycle. The selected traveling routes should best represent the actual network and the typical traffic flow conditions affected by spatial or temporal conditions such as land use, road type, topography, availability of signalized intersections and population density in that area. Moreover, it is essential to consider the vertical alignment of the road as well because gradient of the road has an impact over vehicles fuel consumption, and it varies significantly on the micro segment scale. Two routes as illustrated in Figures 2 and 3 that are selected based on myBAS operation routes which are F100 route and T102 route. F100 route starting from Terminal MBKT, along the Kuala Terengganu city and heading back to Terminal MBKT. Meanwhile, T102 starting from Terminal MBKT, through airport and ending at Jeti Merang. Both routes are chosen because they are the most common routes used by citizen as well as foreigner to travel along small landmass of Kuala Terengganu city. 


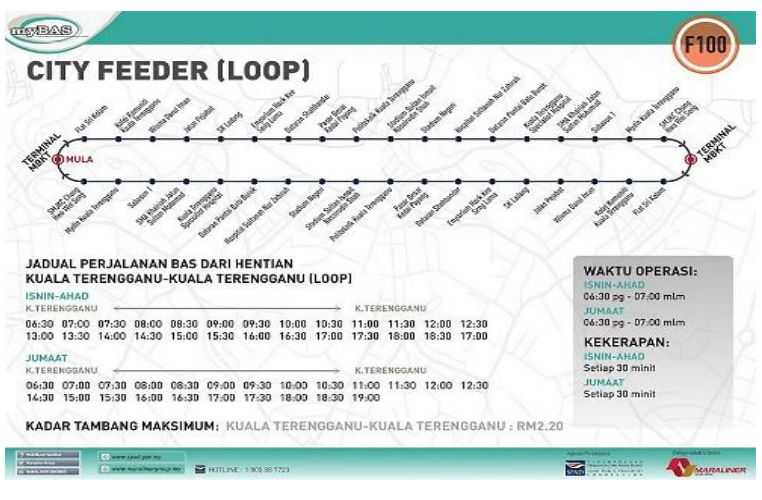

Figure 2. Route 1: F100 route of myBAS

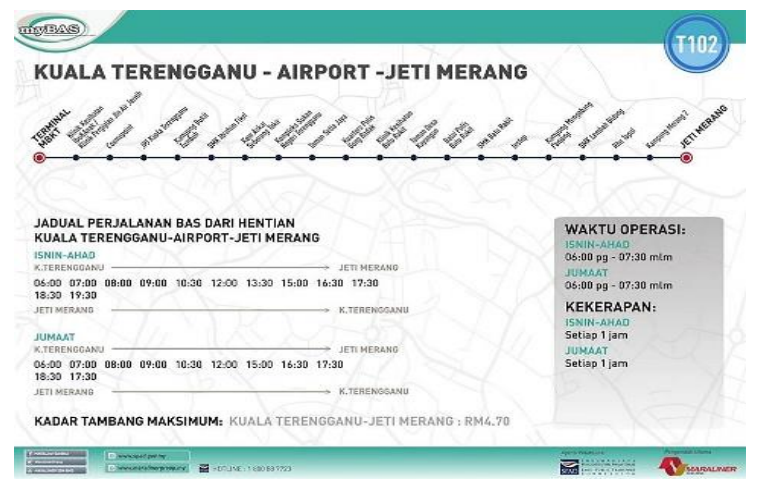

Figure 3. Route 2: T102 route of myBAS

\subsection{Data collection and micro-trips}

For each route 10 test runs data were collected. On-board measurement [24] method is used as data collection method for myBAS driving cycle where the GPS speed was installed as a tracking tool and second by second the speed of driving pattern data is recorded as the bus travel along the selected routes. Because of an irregular and aggressive driving behaviour and pattern in Kuala Terengganu city, on-board method was the finest to be applied and could possibly prevent from any accident that might happen. Besides, on-board measurement is an accurate method for measuring the exhaust emissions.

In this research, a partitioning approach based on the micro-trips was proposed in order to analyse the driving data. Micro-trips well-defined as the driving activity between adjacent stops with including the leading idle time [25]. The actual driving data is split into micro journeys and allocated according to average rates to distinct bins. The cycle was built using micro-trips that required for driving feature extraction and the driving data clustering.

\subsection{Development driving cycle by k-means clustering method}

Micro-trips are choosing in develoed of driving cycle because it can be defined as driving activity between adjacent stops, including leading idle period. Using this method, the real data is separated into micro-trips and assigned into different bins according to average speeds. The complete data must be divided into a number of micro trips. Many micro trips can be acquired after this process for all collected data then the micro-trips will be clustered into several groups using k-means clustering method. The k-means algorithm attempts to solve the clustering problem by optimizing a given metric. The process of partitioning will be done into a given set of $\mathrm{n}$ points into a number, say $\mathrm{K}$, of groups (or, clusters), based on some similarity or dissimilarity of metric [26]. K-means algorithms steps are briefly outlined below:

Step 1: Decide on a value for $k$. In this study, the value of $k$ is based on traffic condition. (Free, congested and medium traffic condition)

Step 2: Initialize the $k$ cluster centres (randomly, if necessary)

Step 3: Decide the class memberships of the total data, $\mathrm{N}$ by assigning them to the nearest cluster centre.

Step 4: Re-estimate the $k$-cluster centres, by assuming the memberships found above are correct.

Step 5: If none of the $\mathrm{N}$ data changed memberships in the last iteration, exit.

Otherwise go to step 3. Subsequently, driving features must first be extracted before clustering the micro-trips. Two common driving features have been used in this study, which are the average speed and the idle time percentage. These two parameters have been selected because they have the greatest emission impacts [13]. The average speed and percentage of idle were plotted in 2-dimensional feature space as shown in Figure 4 after the extraction of parameters process.

Consequently, micro-trips are clustered into 3 groups using k-means clustering method as shown in Figure 5. Each group has its own characteristics and represents various conditions of traffic. Cluster 1 represented for clear traffic flow condition, cluster 2 represented for medium traffic flow condition and, finally, cluster 3 represented for congested traffic flow condition.

Therefore, the legislatures of micro-trips of each cluster are determined to construct the driving cycle after all the micro-trips have been clustered. As representative micro-trips, the nearest micro-trips to the cluster centre are considered. Figures 6, 7, and 8 illustrated the representative of micro-trips for each group clustering. In order to produce the final driving cycle of myBAS for route 1 and route 2 , all these micro-trips then be combined altogether. 


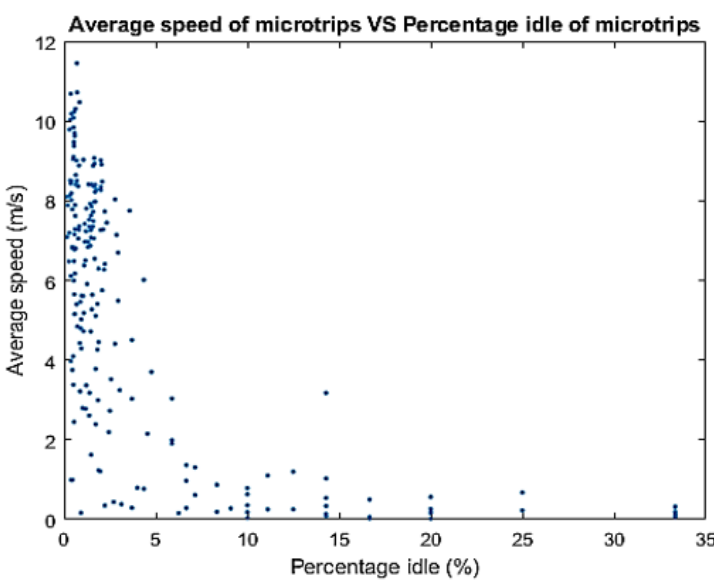

Figure 4. Average speed of micro-trips vs Percentage idle of micro-trips

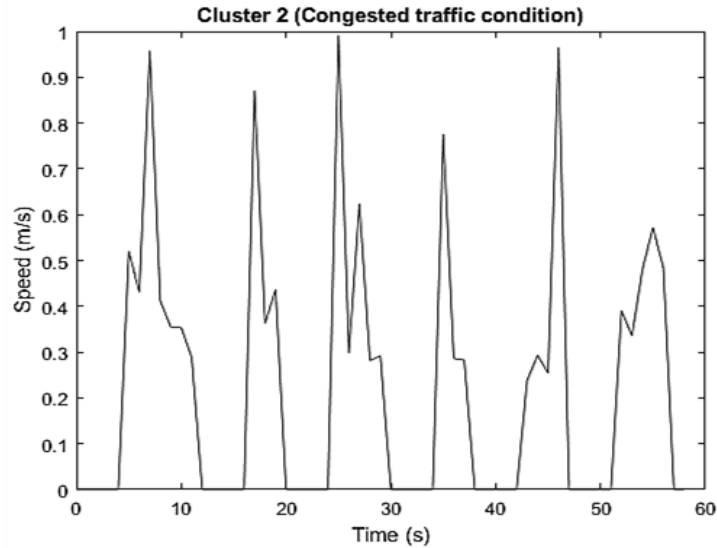

Figure 6. Congested traffic condition

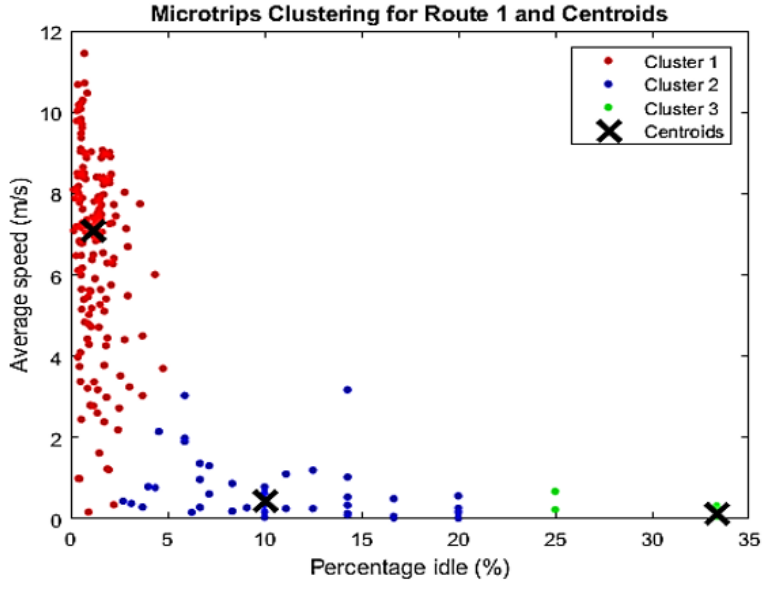

Figure 5. Clustering micro-trips for myBAS

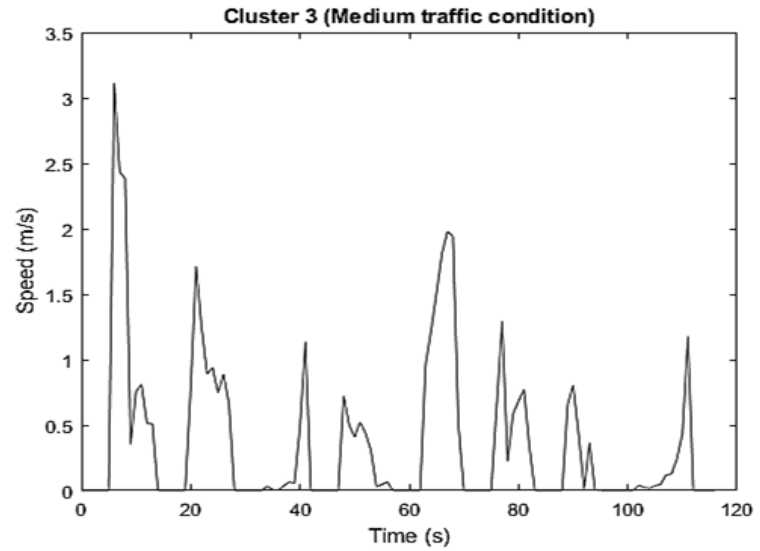

Figure 7. Medium traffic condition

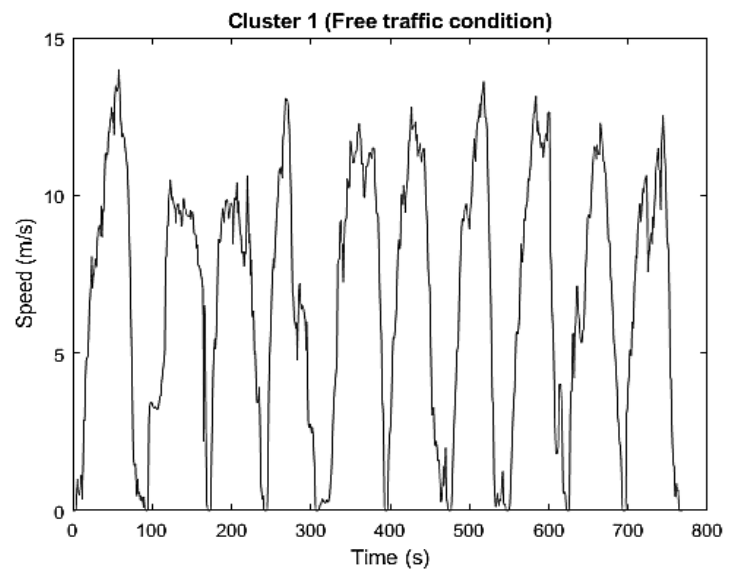

Figure 8. Free traffic condition

\section{RESULTS AND DISCUSSION}

The outcomes of the development of driving cycle for Kuala Terengganu city is deliberated in this section. Furthermore, the fuel consumption and emissions also been analysed and determined. 


\subsection{Kuala Terengganu driving cycle development and analysis}

The final development of myBAS driving cycle as shown in Figure 9 for Route 1 and Figure 10 for Route 2. As illustrated in the figure, shows that each route has different driving cycle patterns. Traffic light, road conditions, environmental factors and driver behaviour were the main external factor due to the different in driving cycle development.

The characteristics of Route 1 and Route 2 in Kuala Terengganu city as shows in Table 2 based on the 9 parameters; average speed, average running speed, average acceleration of all acceleration phases, average deceleration of all deceleration phases, time proportion of idling, time proportion of acceleration, time proportion of cruise, time proportion of deceleration, average number of acceleration-deceleration changes within one driving period and root mean square of acceleration.

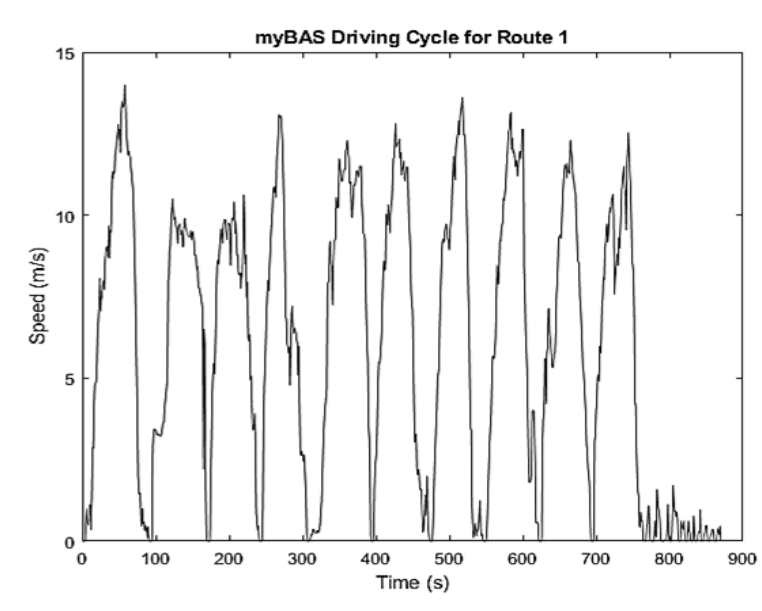

Figure 9. Final myBAS driving cycle for Route 1

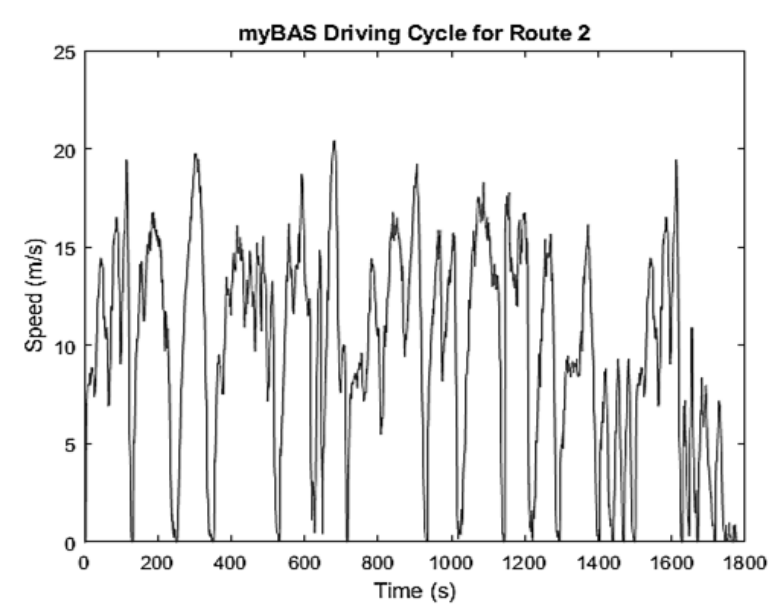

Figure 10. Final myBAS driving cycle for Route 2

$\underline{\text { Table } 2 \text {. The parameters of route } 1 \text { and route } 2 \text { myBAS driving cycle }}$

\begin{tabular}{ccc}
\hline Parameters & Route 1 & Route 2 \\
\hline Average speed $(\mathrm{km} / \mathrm{h})$ & 21.59 & 35.34 \\
Average running speed $(\mathrm{km} / \mathrm{h})$ & 24.41 & 37.38 \\
Average acceleration $\left(\mathrm{m} / \mathrm{s}^{2}\right)$ & 0.48 & 0.60 \\
Average deceleration $\left(\mathrm{m} / \mathrm{s}^{2}\right)$ & -0.53 & -0.61 \\
Time proportion of idling $(\%)$ & 9.15 & 4.32 \\
Time proportion of cruising $(\%)$ & 2.14 & 0.39 \\
Time proportion of acceleration $(\%)$ & 46.45 & 48.06 \\
Time proportion of deceleration $(\%)$ & 42.33 & 47.22 \\
RMS acceleration $\left(\mathrm{m} / \mathrm{s}^{2}\right)$ & 0.71 & 0.98 \\
\hline
\end{tabular}

\subsection{Fuel economy and emissions analysis}

ADVISOR simulation [27] is used to study the effect of driving cycles on vehicle Fuel Consumption (FC) and exhaust emissions such as unburned hydrocarbons (HC), carbon monoxide (CO) and oxides of nitrogen (NOx). The fuel economy and emissions can be determined after the driving cycle have been established by using ADVISOR software as illustrated in Table 3. It can be concluded that the route 1 has higher value of fuel economy which is 27.8631 miles/gallon compared to Route 2 which is 31.5750 miles/gallon. However, there is no major different between Route 1 and route 2 for the value of fuel economy and the gas emissions as the results not only affected by the distance, but also affected by other factors such as number of 'stop-go' conditions, road conditions and others.

Table 3. The fuel economy and emissions of Route 1 and Route 2

\begin{tabular}{ccc}
\hline & Route 1 & Route 2 \\
\hline Fuel economy (miles/gallon) & 27.8631 & 31.5750 \\
Gas emissions (grams/miles): & & \\
CO & 6.0459 & 7.6641 \\
NOx & 0.5790 & 0.5960 \\
HC & 0.6440 & 0.6780 \\
\hline
\end{tabular}




\section{CONCLUSION}

myBAS driving cycle development is carried out using k-means method of clustering microtrips. The data collected based on two operating routes of myBAS that have been selected starting from the predetermined original place to the final destination along route 1 and route 2 . The myBAS driving cycle system is effectively achieved and it can be concluded that the developed driving cycle based on the realword driving behaviour can be used in examining the fuel consumption and emissions. Furthermore, others location or route also can be selected in order to develop driving cycle that based on the real-world driving behaviour for the further research.

\section{ACKNOWLEDGEMENTS}

The financial support of this work by the Fundamental Research Grant Scheme Vot 59453 and facility support by Cas Ligas Sdn. Bhd and the Universiti Malaysia Terengganu, is gratefully acknowledged.

\section{REFERENCES}

[1] J. Wu, C.-H. Zhang, and N.-X. Cui, "Fuzzy energy management strategy for a hybrid electric vehicle based on driving cycle recognition," International Journal of Automotive Technology, vol. 13, no. 7, pp. 1159-1167, 2012.

[2] S. H. Kamble, T. V. Mathew, and G. K. Sharma, "Development of real-world driving cycle: case study of Pune, India," Transportation Research Part D: Transport and Environment, vol. 14, no. 2, pp. 132-140, 2009, doi: 10.1016/j.trd.2008.11.008.

[3] Tong, H.Y., and Hung, W.T. "A framework for developing driving cycles with on-road driving data," Transport reviews, vol. 30, no. 5, pp. 589-615, 2010, doi: 10.1080/01441640903286134.

[4] Barlow, T., Latham, S., Mccrae, I., and Boulter, P., "A reference book of driving cycles for use in the measurement of road vehicle emissions (3rd Version)," TRL Limited, 2009.

[5] Nesamani, K.S., and Subramanian, K.P., "Development of a Driving Cycle for Intra-City Buses in Chennai, India," Atmospheric Environment, vol. 45, pp. 5469-5476, 2011, doi: 10.1016/j.atmosenv.2011.06.067.

[6] Jeon, C.H., et al., "Characterization of Driving Patterns and Development of a Driving Cycle in a Military Area," Transportation Research Part D, vol. 17, no. 7, pp. 519-524, 2012, doi: 10.1016/j.trd.2012.06.004.

[7] Davari, M.M., Jerrelind, J., and Trigell, A.S., "Energy efficiency analyses of a vehicle in modal and transient driving cycles including longitudinal and vertical dynamics," Transportation Research Part D: Transport and Environment, vol. 53, pp. 263-275, 2017, doi: 10.1016/j.trd.2017.04.019.

[8] Huertas, J.I., et al., "A new methodology to determine typical driving cycles for the design of vehicles power trains," Int. Journal on Interactive Design and Manufacturing (IJIDeM), vol. 12, no. 1, pp. 319-326, 2018.

[9] Ashtari, A., Bibeau, E., and Shahidinejad, S., "Using large driving record samples and a stochastic approach for real-world driving cycle construction: Winnipeg driving cycle," Transportation science, vol. 48, no. 2, pp. 170-183, 2012, doi: $10.1287 /$ trsc. 1120.0447 .

[10] Lee, T.K., and Filipi, Z.S., "Synthesis of real-world driving cycles using stochastic process and statistical methodology," International Journal of Vehicle Design, vol. 57, no. 1, pp. 17-36, 2011, doi: 10.1504/IJVD.2011.043590.

[11] Wang, Q., Huo, H., He, K., Yao, Z., and Zhang, Q., "Characterization of vehicle driving patterns and development of driving cycles in Chinese cities," Transportation research part D: transport and environment, vol. 13, no. 5, pp. 289-297, 2008, doi: 10.1016/j.trd.2008.03.003.

[12] Brady, J., and Mahony, M.O., "Development of a driving cycle to evaluate the energy economy of electric vehicles in urban areas," Appl. Energy, vol. 177, pp. 165-178, 2016, doi: 10.1016/j.apenergy.2016.05.094.

[13] Tamsanya, N., and Chungpaibulpatana, S., "Influence of driving cycles on exhaust emissions and fuel consumption of gasoline passenger car in Bangkok," J. Environ. Sci., vol. 21, no. 5, pp. 604-611, 2009, doi: 10.1016/S10010742(08)62314-1.

[14] Vojtisek-Lom M., Fenkl M., Dufek M., Mareš J., "Off-cycle, Real-world emissions of modern light duty diesel vehicles," SAE Technical Paper 2009-24-0148, 2009, doi: 10.4271/2009-24-0148.

[15] Lee J.H., Gitano H., Eu H.S., Mohd Khalil A.S., "Development of motorcycle drive cycles for Malaysia," SAE Technical Paper No. 2010-32-0041, 2010, doi: 10.4271/2010-32-0041.

[16] Oropeza R.G., S. Samuel, Hassaneen A.E., Morrey D., "Evaluation of fuel consumption and exhaust emission levels from a EURO-IV vehicle for realworld driving in Mexico city," SAE Technical Paper No. 2009-01-1824, 2009, doi: 10.4271/2009-01-1824.

[17] Wi H, Park J, Lee J-h, Kim W, Kim Y., "Development of a city bus driving cycle in seoul based on the actual patterns of urban bus driving," SAE Technical Paper No. 2009-01-2914, 2009, doi: 10.4271/2009-01-2914.

[18] Bata, R., Yacoub, Y., Wang, W., Lyons, D., Gambino, M., and Rideout, G., "Heavy duty testing cycles: survey and comparison," SAE transactions, pp. 450-462, 1994, doi: https://www.jstor.org/stable/44473364.

[19] Dia, Z., Eisinger, D. and Niemeier, D., "Driving Cycles: A New Cycle-Building Method That Better Represents Real-World Emissions," University of California, Davis., 2008.

[20] Kin, W.P., and Mao, C.K., "Development of a vehicle driving cycle for Macau," Journal of Macau Studies, vol. 50, pp. 121-131, 2009. 
[21] Jiang, P., Shi, Q., Chen, W., Li, Y., and Li, Q., "Investigation of a new construction method of vehicle driving cycle," Proceedings of the Second International Conference on Intelligent Computation Technology and Automation. Changsha, Hunan, China, vol. 4, pp. 210-214, 2009, doi:10.1109/ICICTA.2009.766.

[22] Seers, P., Nachin, G., and Glaus, M., "Development of two driving cycles for utility vehicles," Transportation Research Part D: Transport and Environment, vol. 41, pp. 377-385, 2015, doi: 10.1016/j.trd.2015.10.013.

[23] Zhang, B., Gao, X., Xiong, X., Wang, X., and Yang, H., "Development of the driving cycle for Dalian City," Proceedings of the 8 th International Conference on Future Generation Communication and Networking. Haikou, China, pp. 60-63, 2014, doi: 10.1109/FGCN.2014.22.

[24] Tong H.Y., Hung W.T., Cheung C.S., "On-road motor vehicle emissions and fuel consumption in urban driving conditions," Journal of the Air \& Waste Management Association, vol. 50, no. 4, pp. 543-554, 2000, doi: 10.1080/10473289.2000.10464041

[25] Maulik, U., and Bandyopadhyay, S., "Genetic algorithm based clustering technique," Pattern Recognition, vol. 33, no. 9, pp. 1455-1465, 2002, doi: 10.1016/S0031-3203(99)00137-5.

[26] Fotouhi, A., and Montazeri-Gh, M., "Tehran driving cycle development using the k-means clustering method. Scientia Iranica," Transactions A: Civil Engineering, vol. 20, no. 2, pp. 286-293, 2013, doi: 10.1016/j.scient.2013.04.001.

[27] Markel, T., et al., "ADVISOR: a systems analysis tool for advanced vehicle modeling," Journal of power sources, vol. 110, no. 2, pp. 255-266, 2002, doi: 10.1016/S0378-7753(02)00189-1.

\section{BIOGRAPHIES OF AUTHORS}

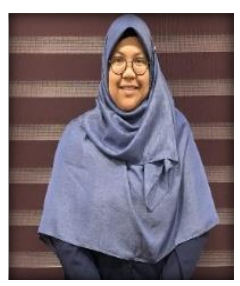

J. S. Norbakyah received the Bachelor of Applied Science (Physics Electronic and Instrumentation) and MSc and PhD from Universiti Malaysia Terengganu, Terengganu, in 2009, 2014 and 2019 respectively. She currently working as a lecturer at Univerisiti Malaysia Terengganu, Malaysia. Her main research interest is Electric Vehicle, Hybrid Electric Vehicle, Plug in Hybrid Vehicle, Modelling and simulation and renewable energy

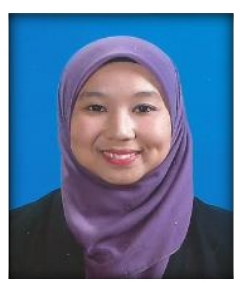

I. N. Anida received the Bachelor of Engineering (Mechatronics) from International Islamic University Malaysia, Gombak in 2015 and currently pursuit her Master Degree in Physics (Renewable Energy) in Universiti Malaysia Terengganu. Her main research interest is Plug in Hybrid Vehicle, driving cycle, energy rate and emissions.

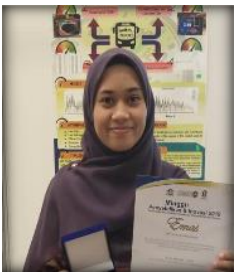

M. I. Nordiyana received the Bachelor of Applied Science (Physics Electronic and Instrumentation) from Universiti Malaysia Terengganu, Terengganu, in 2019. Her main research interest is driving cycle, energy rate and emissions.

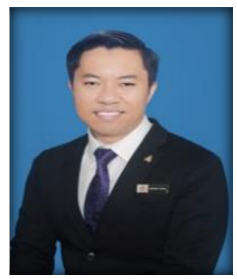

Ahmad F. Ayob received his Bachelor Degree in Mechanical Engineering with Honors in 2006 (Malaya), and Ph. D in Mechanical Engineering in 2011 (New South Wales). His work is mainly focusing in design optimization and naval architecture via the use of artificial intelligence methods. Currently A. F. Ayob is serving as an Associate Professor in the Universiti Malaysia Terengganu.

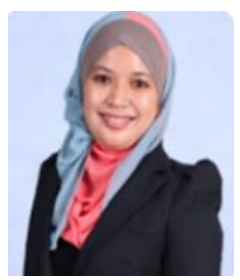

A. R. Salisa received the B.E. and M.E. in Electrical \& Electronics Engineering from University of Technology Petronas, Perak, Malaysia in 2004 and 2006, respectively while Ph.D. in Optimal Energy Management Strategy for the University of Technology Sydney Plug-In Hybrid Electric Vehicles from University of Technology Sydney (UTS), Australia. She is currently working as a senior lecturer at University Malaysia Terengganu, Malaysia. Her research interests are in Hybrid Electric Vehicles, innovation powertrain, simulation and modeling, energy management strategy, driving cycles, fuel economy, emissions and optimization. 